\title{
ETHANOLIC EXTRACTS FROM AGRO-INDUSTRIAL CO-PRODUCTS ENHANCE OXIDATIVE STABILITY OF CANDELILLA WAX OR CELLULOSES DERIVATIVES OLEOGELS
}

\author{
- Research paper -
}

\author{
Beatriz Mariel FERRER-GONZÁLEZ*, Norma Leticia FLORES-MARTÍNEZ***, Alfonso \\ TOTOSAUS*1
}

\author{
*Food science lab and pilot plant, Tecnológico Nacional de México/TES Ecatepec. Av. Tecnológico \\ esq. Av. Central s/n, Ecatepec 55210, Estado de México, México. \\ **Agroindustrial engineering Department, Universidad Politécnica de Guanajuato. Avenida \\ Universidad Sur 1001, Cortazar, Guanajuato, México.
}

\begin{abstract}
Ethanol oleoresins obtained from orange peel, pea pod, or pomegranate peel were employed to enrich soybean oil before elaborating two types of oleogels, one made with candelilla wax, another made with a mixture of celluloses derivatives, in order to determine their effect on oleogel oxidative stability. Orange peel oleoresin obtained a higher amount of polyphenols as catechol acid equivalent $(9.09 \mathrm{meq} / \mathrm{g})$, as compared to pea pod oleoresin or pomegranate peel (8.80 and 8.55, respectively), although pomegranate peel presented the higher TEAC (1.67, twice than the other samples). Oleogels elaborated with celluloses were presented better oxidative stability (oxidative rancidity and peroxide index) as compared to samples elaborated with candelilla wax, since waxes minor constituents employed as oleogelators could promote prooxidant activity. Samples with pomegranate oleoresin presented enhanced oxidative stability. Candelilla wax has a more marked effect on the oleogels thermal properties of due to their influence on fatty acids crystallization, because in celluloses oleogels the mechanism of gelation does not imply the formation of a highly ordered secondary structure. This finding opens the possibility to, on one hand, use oleoresins to enhance the oxidative stability of oleogels; and on the other hand, to select the oleogelator, waxes, or celluloses, based on thermal properties and other aspects, depending on the further application of oleogel thinking in oleogel thermoreversible capacity.
\end{abstract}

Keywords: Oleogel, candelilla wax, celluloses, oxidative stability, agro-industrial co-product

\section{INTRODUCTION}

Food waste is considered products that are not directly related to human consumption, although not included in the strict definition of food waste, the use of leftovers of agro-industry must be considered, in addition to those derived from production (damage during harvesting). postharvest manipulation and storage (degradation and spillage during handling, and transport), processing (industrial or domestic), distribution, and consumption at the household level. Fruit and vegetable produce the highest amounts of coproducts, followed by animal origin products, and the wine industry (Naumovski et al., 2017).

Oleogels preparation includes edible oil mixed with an organogelator agent at high temperature with continuous mixing, with oxidative effect on lipids

Received: 14.02 .2021

Accepted in revised form: 30.05 .2021 in the oleogel (Lim et al., 2017). The high temperature and constant mixing applied to oil and structuring agents (celluloses or waxes, for example) create the circumstances to accelerate the auto-oxidative process in edible oils, since oil rancidity is not desirable in oleogels for food application (Gravelle et al., 2012). The presence of primary oxidative products, like lipid, is the result of the lipid peroxidation self-propagating process, intermediate products in the lipids auto-oxidation process (Gravelle et al., 2016). Oxidative stability of oleogels in food products is important since although immobilized oil in oleogel may retard oxidation, fatty acids oxidation could exert negative effect that can be prevented adding antioxidants (Hwang, 2020). In certain edible oil, like virgin pure oil, the presence of natural antioxidant compounds (polyphenols) seems to be enough to maintain oleogel oxidative stability, with no effect of

${ }^{1}$ Corresponding author. E-Mail address: atotosaus@tese.edu.mx 
oleogelation on the degradation of the antioxidant compounds (Öğ̈̈tcü and Yılmaz, 2015).

Edible oils, enriched with natural antioxidants, obtained from low-cost resources, as agro-industrial co-products, using eco-friendly, unconventional extraction methods, presented comparable or higher antioxidant activity and thermal stability than oils added with synthetic antioxidants (Blasi \& Cossignani, 2020). The antioxidant capacity of polyphenols is to prevent radical chain reactions of oxidation, stopping initiation and propagation steps, delaying degradation reactions, serving as hydrogen donator, reducing agent, or single oxygen quencher (Babbar et al., 2014). For example, tomato waste extracts with low levels of lycopene and $\beta$-carotene

\section{MATERIALS AND METHODS}

\section{Liquid-solid extraction}

Agro-industrial co-products generated in Megalopolis (Mexico City and Estado de Mexico co-urban area) were recollected in fresh fruit and vegetable processing facilities and markets from May to August in 2018. Orange peel (Citrus sinensis), pea pod (Pisum sativum), and pomegranate peel (Punica granatum). Samples were washed with tap water, drained, and dry at 50$60{ }^{\circ} \mathrm{C}$ during $24-36 \mathrm{~h}$ in a Weston $74-1001-\mathrm{W}$ oven (Weston Products LLC, Strongsville OH). Dry samples were stored in plastic bags until oleoresin extraction. To obtain ethanolic extracts, $10 \mathrm{~g}$ of sample were placed in Whatman cellulose cartridges plus $100 \mathrm{~mL}$ of ethanol $70 \%$ ( $\mathrm{vol} / \mathrm{vol}$ ) in Soxhlet equipment to distillate at least during 2 . Oleoresins were filtered and centrifuged at 2,600 $\times \mathrm{g}$ for $15 \mathrm{~min}$ to eliminate solid residues, and stored in amber flasks at $4{ }^{\circ} \mathrm{C}$.

\section{Total polyphenols quantification}

Total polyphenols content was determined according to the methodology reported by Singleton and Rossi (1965). One $\mathrm{mL}$ of Folin-Ciocalteu reactive was added to $1 \mathrm{~mL}$ of sample and mixed with $8 \mathrm{~mL}$ of $0.7 \mathrm{M} \mathrm{Na}_{2} \mathrm{CO}_{3}$. The mixture was allowed to stand $2 \mathrm{~h}$ at room temperature in the dark and absorbance was measured at $765 \mathrm{~nm}$ and extrapolated against a catechol standard curve ( 0 to $100 \mathrm{mg} / \mathrm{mL}$ ).

\section{Antioxidant capacity}

2,2'-Azino-bis (3-ethylbenzothiazoline-6-sulfonic acid) diammonium salt stock solution $(7 \mathrm{mM})$ was made react with $2.45 \mathrm{mM} \mathrm{K}_{2} \mathrm{O}_{8} \mathrm{~S}_{2}$ during $12 \mathrm{~h}$ in the dark to produce an ABTS radical cation. Absorbance $(734 \mathrm{~nm})$ was adjusted with $70 \%$ presented moderate antioxidant activity and can be employed as natural antioxidants in industrialized edible oils, with a similar antioxidant effect as BHT (Freitas et al., 2020). In the same manner, polyphenols as oleuropein, hydroxytyrosol, and quercetin extracted from olive leaf extract were employed to supplementation of olive oil, sunflower oil, palm oil, and vegetable shortening, where both antioxidant capacity and oxidative stability were substantially improved for all the oils studied (Salta et al., 2007). In this view, the objective of this work was to elaborate on two types of oleogels, one made with candelilla wax, another made with a mixture of cellulose derivatives, with soybean oil plus orange peel, pea pod, or pomegranate peel oleoresins, to enhance oleogel oxidative stability.

ethanol of the stock solution to 0.700. Stock solutions of each one of the agro-industrial coproducts oleoresins (orange peel, pea pod, or pomegranate peel) were diluted until produce a blank inhibition absorbance between $20-80 \%$ in a $10 \mathrm{~mL}$ aliquot. After the addition of $1.0 \mathrm{~mL}$ of ABTS stock solution to $10 \mathrm{~mL}$ of diluted oleoresins or Trolox (6-hydroxy-2,5,7,8-tetramethylchroman2-carboxylic acid) standards (0-15 mM) in ethanol, absorbance was monitored during 10 min (reading $60 \mathrm{~s})$ after mixing. The percentage inhibition of absorbance at $734 \mathrm{~nm}$ is calculated and plotted as a function of the concentration of antioxidants and Trolox for the standard reference data (Re et al., 1999).

\section{Oleogeles elaboration}

To establish the effect of the orange peel, pea pod, or pomegranate peel oleoresins on oxidative stability of oleogels, $1 \%(\mathrm{v} / \mathrm{v})$ of each one of the oleoresins were mixed with Nutrioli ${ }^{\circledR}$ soybean oil (Industrias Ragasa, Monterrey, Mexico) before oleogel elaboration.

Candelilla wax oleogel was prepared in agree to the reported by Toro-Vázquez et al. (2007). Soybean oil was heated at $90{ }^{\circ} \mathrm{C}$ to add candelilla wax (Bliss Nature, Mexico City) in 97:3 proportion (v/v). After cooling the heating process, molten Candelilla wax oleogels were kept in bakers covered with aluminium foil before storage.

A mixture of celluloses $(11 \%, \mathrm{w} / \mathrm{v})$ comprising $7.370 \%$ of ethyl cellulose $\eta=100 \mathrm{cP}$ (SigmaAldrich, St. Louis, USA), $1.815 \%$ of alphacellulose (Sigma-Aldrich, St. Louis, USA), and $1.815 \%$ of Avicel RC-591 (FMC Biopolymers Mexico, Mexico City) plus $3.67 \%$ (w/v) of sorbitan monostearate as surfactant were heated at $120{ }^{\circ} \mathrm{C}$ into $85.33 \%$ of soybean oil with magnetic stirring 
until ingredients solubilization. After cooling the heating process, molten celluloses mixture oleogels were kept in bakers covered with aluminium foil before storage.

\section{Oxidative rancidity}

The thiobarbituric acid methodology was employed to determinate the amount of malonaldehyde, as oxidative rancidity. $100 \mathrm{mg}$ of oleogel was weighed and dissolved in $5 \mathrm{~mL}$ of 1-butanol before transfer to a $25 \mathrm{~mL}$ volumetric flask and bring to the volume with 1-butanol. In screw-cap glass tubes, $5 \mathrm{~mL}$ of sample solution were mixed with $5 \mathrm{~mL}$ of $0.014 \mathrm{M}$ 2-thiobarbituric acid solution in 1-butanol. Tubes were vortexed and incubated $2 \mathrm{~h}$ in boiling water. Tubes were cooled under running tap water for 10 min and absorbance measured at $532 \mathrm{~nm}$ (Yun and Surh, 2012). Concentration of malonaldehyde ( $\mathrm{mg} / \mathrm{kg}$ of sample) was calculated extrapolating the absorbance against $0.0004 \quad \mathrm{M}$ 1,1,3,3tetraethoxypropane in 1-butanol solution, making the pertinent dilutions.

\section{Peroxide value}

Peroxide value was determined according to the AOAC Official Method 965.33 (AOAC, 1999). Five $\mathrm{g}$ of sample were dissolved in $30 \mathrm{~mL}$ of a $\mathrm{CH}_{3} \mathrm{COOH}-\mathrm{CHCl}_{3}$ solution $(1: 1 \mathrm{v} / \mathrm{v}) .0 .5 \mathrm{~mL}$ of a saturated freshly prepared KI solution was added and after shaking for one minute, $30 \mathrm{~mL}$ of distilled water was added. The sample was titrated with 0.1 $\mathrm{N} \mathrm{Na}_{2} \mathrm{~S}_{2} \mathrm{O}_{3}$ until the yellow colour was almost gone. $0.5 \mathrm{~mL}$ of a $1 \%$ freshly prepared starch solution was added to continue titration by shaking vigorously

\section{RESULTS AND DISCUSSION}

Polyphenols content and Trolox equivalent antioxidant capacity of the oleoresins obtained from agro-industrial co-products are listed in Table 1. The extracted polyphenols content was similar for all the samples, but the antioxidant capacity was higher for pomegranate peel extract, as compared to orange peel extract or pea pod extract. Pea pods showed good phenolic content and antioxidant ability, indicating that phenolic compounds are responsible for antiradical activity in the methanolic extracts of the vegetable residues (Babbar et al., 2014), besides to a higher half-maximal effective concentration $\left(\mathrm{EC}_{50}\right)$, as compared to ascorbic acid (Mateos-Aparicio et al., 2012). Pomegranate peel antioxidant property is directly related to the presence of specific phenolic compounds, like phenolic acids, flavonoids, punicalin, and hydrolysable tannins, including punicalagins, until the blue colour had disappeared. Peroxide value was reported as $\mathrm{O}_{2}$ meq per $\mathrm{kg}$ of sample.

\section{Differential scanning calorimetry}

Oleogel samples were analysed according to the methodology reported by Pérez-Monterrosa et al. (2016), in a Mettler DSC1 differential scanning calorimeter (Mettler Toledo, Columbus, USA), calibrated with indium and nitrogen flow purge (20 $\mathrm{mL} / \mathrm{min}$ ), employing an empty pan as reference. Oleogel samples $(0.006 \pm 0.001 \mathrm{~g})$ were weighted in $40 \mu \mathrm{L}$ crucibles aluminium pans and sealed and to erase any memory structure, the samples were heated at $5{ }^{\circ} \mathrm{C} / \mathrm{min}$ from $25{ }^{\circ} \mathrm{C}$ to $80{ }^{\circ} \mathrm{C}$ and kept at $80^{\circ} \mathrm{C}$ for $10 \mathrm{~min}$, and then cooled at $5^{\circ} \mathrm{C} / \mathrm{min}$ from $80{ }^{\circ} \mathrm{C}$ to $25^{\circ} \mathrm{C}$.

\section{Experimental design and data analysis}

The effect of oleoresin type on the different oleogels properties (malonaldehyde content peroxide value) during storage was evaluated with the proposed model:

$y_{i j k}=\mu+\alpha_{i}+\beta_{j}+\gamma_{k}+\epsilon$ where $y_{i j k}$ represents oxidative rancidity or peroxide index at the $i$-th oleoresin type and $\mathrm{j}$-th oleogel type (celluloses or candelilla wax) and $\mathrm{k}$-th storage time; $\mu$ is the overall mean; $\alpha_{\mathrm{i}}$ is the main effect of agro-industrial coproduct oleoresin, $\beta_{\mathrm{j}}$ is the main effect of the oleogel type and $\gamma_{\mathrm{k}}$ is the main effect of storage time; and $\epsilon$ is the error terms presumed $\mathrm{N}\left(\mu, \sigma^{2}\right)$ (Der and Everitt, 2001). PROC ANOVA procedure in SAS Software v 8.0 (SAS System, Cary, NC, USA) was employed to analyse experimental data and significant means differences with the Duncan means test.

anthocyanins, and ellagic acid derivatives (Fawole and Opara, 2016). Orange peel extracts possess a great number of phenolic compounds with potent antioxidant activity (Park et al., 2014). In pea pod extracts, the maximum total phenolic content and maximum antioxidant activity determined using the DPPH method was obtained by using ethanol $(12.12 \pm 0.19 \mathrm{mg}$ GAE/g, and $81.96 \pm 0.15 \%$, respectively), although the maximum extraction yield was obtained with water (Ghorbani et al., 2016). This demonstrated antioxidant activity of the polyphenols extracted from the agro-industrial can be effectively employed as natural antioxidants in oleogel elaboration, to enhance edible oils protection from oxidative damage during oleogel elaboration. Regarding the application of oleoresins to edible oil in oleogel elaboration, oleogels made with the mixture of celluloses obtained oxidative rancidity values significantly $(\mathrm{P}>0.05)$ lower than the oleogels made with candelilla wax. In the same 
manner, pomegranate oleoresin containing samples presented significantly $(\mathrm{P}>0.05)$ lower rancidity values than pea pod or orange peel samples, where control obtained the higher values. Oleogels oxidative rancidity values were significantly $(\mathrm{P}>0.05)$ increasing with storage time (Table 2). In peroxide values, there was not a significant $(\mathrm{P}<0.05)$ difference between candelilla oleogel wax or celluloses oleogel samples. Control samples obtained significantly ( $\mathrm{P}>$.0.5) higher peroxide values, where pomegranate oleoresin samples resulted in the ones with lower values. During storage, peroxide values were significantly $(\mathrm{P}>0.05)$ increasing with time (Table 3).

Slower diffusion of oxygen in structured oils as oleogels as compared to liquid oils resulted in a better oxidative stability (Yi et al. 2017). This, plus the antioxidant effect of the oleoresins with antioxidants from orange peel, pea pod, and pomegranate peel helped to retard even more the oxidative process. Although the restriction of oil mobility and migration via organogelation retarded oil oxidation during storage in oleogels made with waxes (Lim et al., 2017; Martins et al., 2017), minor components in waxes employed as oleogelators could exert prooxidant activity (Hwang 2020). This could be the reason why Candelilla wax oleogels presented higher oxidative rancidity and higher peroxide values, related to lower oxidative stability, than to cellulose derivatives oleogels. In the same manner, rancidity and peroxide values tended to increase during storage (Lim et al., 2017; Yi et al. 2017). Pomegranate peel oleoresin resulted in better oleogels oxidative stability.

Table 1. Total polyphenols content and Trolox equivalent antioxidant capacity (TEAC) of the oleoresin from the different agro-industrial co-products.

\begin{tabular}{|l|l|l|}
\hline Sample & $\begin{array}{l}\text { Total polyphenols (mg of } \\
\text { catechol eq/g of the sample) }\end{array}$ & TEAC \\
\hline Orange peel oleoresin & $9.09 \pm 0.01$ & $0.82 \pm 0.01$ \\
\hline Pomegranate peel oleoresin & $8.55 \pm 0.02$ & $1.67 \pm 0.01$ \\
\hline Pea pod oleoresin & $8.80 \pm 0.06$ & $0.82 \pm 0.01$ \\
\hline
\end{tabular}

Table 2. Oxidative rancidity ( $\mathrm{mg}$ of malonaldehyde per $\mathrm{g}$ of sample) of candelilla wax or celluloses oleogels elaborated with different agroindustrial coproducts oleoresin during storage.

\begin{tabular}{|c|c|c|c|c|c|c|}
\hline \multirow{2}{*}{ Oleogel type } & \multirow{2}{*}{ Oleoresin type } & \multicolumn{5}{|c|}{ Storage time } \\
\hline & & 1 & 15 & 30 & 45 & 60 \\
\hline \multirow{4}{*}{$\begin{array}{l}\text { Candelilla } \\
\text { wax }\end{array}$} & Control & $\begin{array}{l}3.05 \pm 0.18 \\
\text { A, a, h }\end{array}$ & $\begin{array}{l}3.55 \pm 1.15 \\
A, a, h\end{array}$ & $\begin{array}{l}3.62 \pm 0.90 \\
\text { A, a,g }\end{array}$ & $\begin{array}{l}4.38 \pm 0.13 \\
\mathrm{~B}, \mathrm{a}, \mathrm{f}\end{array}$ & $\begin{array}{l}4.87 \pm 0.10 \\
\text { A, a, e }\end{array}$ \\
\hline & $\begin{array}{l}\text { Pomegranate } \\
\text { peel }\end{array}$ & $\begin{array}{l}2.12 \pm 0.52 \\
A, d, h\end{array}$ & $\begin{array}{l}2.75 \pm 0.41 \\
A, d, h\end{array}$ & $\begin{array}{l}3.00 \pm 0.57 \\
\mathrm{~A}, \mathrm{~d}, \mathrm{~g}\end{array}$ & $\begin{array}{l}3.22 \pm 0.14 \\
\mathrm{~A}, \mathrm{~d}, \mathrm{f}\end{array}$ & $\begin{array}{l}2.80 \pm 0.09 \\
\mathrm{~A}, \mathrm{~d}, \mathrm{e}\end{array}$ \\
\hline & Orange peel & $\begin{array}{l}2.84 \pm 0.15 \\
\mathrm{~A}, \mathrm{~b}, \mathrm{~h}\end{array}$ & $\begin{array}{l}2.93 \pm 0.90 \\
\mathrm{~A}, \mathrm{~b}, \mathrm{~h}\end{array}$ & $\begin{array}{l}3.33 \pm 0.33 \\
\mathrm{~A}, \mathrm{~b}, \mathrm{~g}\end{array}$ & $\begin{array}{l}3.44 \pm 0.80 \\
\text { A, b, f }\end{array}$ & $\begin{array}{l}3.18 \pm 0.03 \\
\text { A, b, e }\end{array}$ \\
\hline & Pea pod & $\begin{array}{l}2.51 \pm 0.05 \\
\mathrm{~A}, \mathrm{c}, \mathrm{h}\end{array}$ & $\begin{array}{l}3.33 \pm 0.99 \\
\mathrm{~A}, \mathrm{c}, \mathrm{h}\end{array}$ & $\begin{array}{l}3.07 \pm 0.22 \\
\text { A, c, g }\end{array}$ & $\begin{array}{l}3.63 \pm 0.85 \\
\mathrm{~A}, \mathrm{c}, \mathrm{f}\end{array}$ & $\begin{array}{l}2.87 \pm 0.02 \\
\mathrm{~A}, \mathrm{c}, \mathrm{e}\end{array}$ \\
\hline \multirow{4}{*}{ Celluloses } & Control & $\begin{array}{l}2.95 \pm 0.11 \\
B, a, h\end{array}$ & $\begin{array}{l}3.63 \pm 0.40 \\
B, a, h\end{array}$ & $\begin{array}{l}4.10 \pm 0.57 \\
\mathrm{~B}, \mathrm{a}, \mathrm{g}\end{array}$ & $\begin{array}{l}3.70 \pm 0.29 \\
\mathrm{~A}, \mathrm{a}, \mathrm{f}\end{array}$ & $\begin{array}{l}3.30 \pm 0.30 \\
\mathrm{~B}, \mathrm{a}, \mathrm{e}\end{array}$ \\
\hline & $\begin{array}{l}\text { Pomegranate } \\
\text { peel }\end{array}$ & $\begin{array}{l}1.59 \pm 0.52 \\
B, d, h\end{array}$ & $\begin{array}{l}2.38 \pm 0.22 \\
B, d, h\end{array}$ & $\begin{array}{l}2.83 \pm 0.40 \\
B, d, g\end{array}$ & $\begin{array}{l}2.27 \pm 0.75 \\
B, d, f\end{array}$ & $\begin{array}{l}2.84 \pm 0.31 \\
B, d, e\end{array}$ \\
\hline & Orange peel & $\begin{array}{l}2.71 \pm 0.26 \\
\text { B, b, h }\end{array}$ & $\begin{array}{l}2.97 \pm 0.54 \\
B, b, h\end{array}$ & $\begin{array}{l}3.45 \pm 0.08 \\
B, b, g\end{array}$ & $\begin{array}{l}2.47 \pm 0.84 \\
B, b, f\end{array}$ & $\begin{array}{l}3.10 \pm 0.28 \\
\mathrm{~B}, \mathrm{~b}, \mathrm{e}\end{array}$ \\
\hline & Pea pod & $\begin{array}{l}2.15 \pm 0.97 \\
B, c, h\end{array}$ & $\begin{array}{l}3.00 \pm 0.14 \\
\mathrm{~B}, \mathrm{c}, \mathrm{h}\end{array}$ & $\begin{array}{l}3.05 \pm 0.25 \\
\mathrm{~B}, \mathrm{c}, \mathrm{g}\end{array}$ & $\begin{array}{l}2.39 \pm 0.88 \\
\mathrm{~B}, \mathrm{c}, \mathrm{f}\end{array}$ & $\begin{array}{l}2.90 \pm 0.04 \\
\mathrm{~B}, \mathrm{c}, \mathrm{e}\end{array}$ \\
\hline
\end{tabular}

A, B Means with the same letter in the same column are not significantly $(<0.05)$ different for oleogel type.

$\mathrm{a}, \mathrm{b}, \mathrm{c}, \mathrm{d}$ Means with the same letter in the same column are not significantly $(<0.05)$ different for oleoresin type.

$\mathrm{e}, \mathrm{f}, \mathrm{g}, \mathrm{h}$ Means with the same letter in the same row are not significantly $(<0.05)$ different for storage time. 
Table 3. Peroxide index (meq of active oxygen per kilogram) of candelilla wax or celluloses oleogels elaborated with different agro-industrial co-products oleoresin during storage.

\begin{tabular}{|c|c|c|c|c|c|c|}
\hline \multirow{2}{*}{ Oleogel type } & \multirow{2}{*}{ Oleoresin type } & \multicolumn{5}{|c|}{ Storage time } \\
\hline & & 1 & 15 & 30 & 45 & 60 \\
\hline \multirow{4}{*}{$\begin{array}{l}\text { Candelilla } \\
\text { wax }\end{array}$} & Control & $\begin{array}{l}61.5 \pm 1.53 \\
A, a, h\end{array}$ & $\begin{array}{l}43.5 \pm 1.85 \\
\text { A, a, g }\end{array}$ & $\begin{array}{l}46.5 \pm 1.59 \\
A, a, f\end{array}$ & $\begin{array}{l}51.5 \pm 2.13 \\
\mathrm{~B}, \mathrm{a}, \mathrm{e}\end{array}$ & $\begin{array}{l}53.5 \pm 2.10 \\
\mathrm{~A}, \mathrm{a}, \mathrm{e}\end{array}$ \\
\hline & $\begin{array}{l}\text { Pomegranate } \\
\text { peel }\end{array}$ & $\begin{array}{l}43.5 \pm 1.64 \\
A, d, h\end{array}$ & $\begin{array}{l}41.5 \pm 1.90 \\
A, d, g\end{array}$ & $\begin{array}{l}45.5 \pm 1.73 \\
\text { A, d, f }\end{array}$ & $\begin{array}{l}51.5 \pm 1.80 \\
A, d, e\end{array}$ & $\begin{array}{l}50.5 \pm 2.03 \\
A, d, e\end{array}$ \\
\hline & Orange peel & $\begin{array}{l}51.5 \pm 1.49 \\
\mathrm{~A}, \mathrm{c}, \mathrm{h}\end{array}$ & $\begin{array}{l}45.5 \pm 1.79 \\
\mathrm{~A}, \mathrm{c}, \mathrm{g}\end{array}$ & $\begin{array}{l}38.5 \pm 1.72 \\
\mathrm{~A}, \mathrm{c}, \mathrm{f}\end{array}$ & $\begin{array}{l}50.5 \pm 2.05 \\
\mathrm{~A}, \mathrm{c}, \mathrm{e}\end{array}$ & $\begin{array}{l}55.1 \pm 2.02 \\
\mathrm{~A}, \mathrm{c}, \mathrm{e}\end{array}$ \\
\hline & Pea pod & $\begin{array}{l}65.5 \pm 1.52 \\
A, b, h\end{array}$ & $\begin{array}{l}44.5 \pm 1.67 \\
A, b, g\end{array}$ & $\begin{array}{l}41.5 \pm 2.57 \\
\mathrm{~A}, \mathrm{~b}, \mathrm{f}\end{array}$ & $\begin{array}{l}53.5 \pm 1.14 \\
A, b, e\end{array}$ & $\begin{array}{l}55.5 \pm 2.09 \\
A, b, e\end{array}$ \\
\hline \multirow{4}{*}{ Celluloses } & Control & $\begin{array}{l}50.5 \pm 1.27 \\
B, a, h\end{array}$ & $\begin{array}{l}69.5 \pm 1.76 \\
B, a, g\end{array}$ & $\begin{array}{l}61.5 \pm 2.51 \\
B, a, f\end{array}$ & $\begin{array}{l}45.5 \pm 1.29 \\
B, a, e\end{array}$ & $\begin{array}{l}62.5 \pm 1.30 \\
B, a, e\end{array}$ \\
\hline & $\begin{array}{l}\text { Pomegranate } \\
\text { peel }\end{array}$ & $\begin{array}{l}58.5 \pm 1.74 \\
B, d, h\end{array}$ & $\begin{array}{l}48.5 \pm 2.55 \\
B, d, g\end{array}$ & $\begin{array}{l}45.5 \pm 1.25 \\
B, d, f\end{array}$ & $\begin{array}{l}56.5 \pm 1.88 \\
B, d, e\end{array}$ & $\begin{array}{l}47.5 \pm 2.04 \\
B, d, e\end{array}$ \\
\hline & Orange peel & $\begin{array}{l}63.5 \pm 2.37 \\
B, c, h\end{array}$ & $\begin{array}{l}67.5 \pm 2.59 \\
B, c, g\end{array}$ & $\begin{array}{l}36.4 \pm 1.08 \\
B, c, f\end{array}$ & $\begin{array}{l}43.5 \pm 1.84 \\
\mathrm{~B}, \mathrm{c}, \mathrm{e}\end{array}$ & $\begin{array}{l}51.5 \pm 2.28 \\
\mathrm{~B}, \mathrm{c}, \mathrm{e}\end{array}$ \\
\hline & Pea pod & $\begin{array}{l}62.5 \pm 1.87 \\
B, b, h\end{array}$ & $\begin{array}{l}62.5 \pm 2.32 \\
\mathrm{~B}, \mathrm{~b}, \mathrm{~g}\end{array}$ & $\begin{array}{l}32.5 \pm 2.40 \\
\mathrm{~B}, \mathrm{~b}, \mathrm{f}\end{array}$ & $\begin{array}{l}40.5 \pm 1.75 \\
B, b, e\end{array}$ & $\begin{array}{l}41.5 \pm 1.31 \\
B, b, e\end{array}$ \\
\hline
\end{tabular}

A, B Means with the same letter in the same column are not significantly $(<0.05)$ different for oleogel type. $\mathrm{a}, \mathrm{b}, \mathrm{c}, \mathrm{d}$ Means with the same letter in the same column are not significantly $(<0.05)$ different for oleoresin type. $\mathrm{e}, \mathrm{f}, \mathrm{g}, \mathrm{h}$ Means with the same letter in the same row are not significantly $(<0.05)$ different for storage time.

\section{Differential scanning calorimetry}

The thermal behaviour of oleogels made with candelilla wax and the different oil with the different oleoresins is shown in Figure 1. Control samples (no added oleoresin) presented three peaks that can be observed at 35,72 , and $80{ }^{\circ} \mathrm{C}$ during heating, and during cooling, there were as well three peaks present at 50 and $65{ }^{\circ} \mathrm{C}$, and a pronounced structure at $42{ }^{\circ} \mathrm{C}$. In the oleogels elaborated with the soybean oil with the different oleoresins, there was a slight shifting of the peaks during the heating and cooling process.

For oleogels elaborated with bee wax, crystallized structures can be observed at 14 and $47^{\circ} \mathrm{C}$, close to the During heating two peaks were observed at 65 and $80{ }^{\circ} \mathrm{C}$, and only two at 40 and $45^{\circ} \mathrm{C}$, being more marked in oleogels with orange peel or pomegranate peel oleoresin.

monoglycerides crystallization temperatures, plus the presence of the unsaturated fatty acids and the crystallization peaks observed at elevated temperatures were related to the content of the saturated fatty acids in the monoglycerides and the beeswax, besides there is an effect due to the interaction between wax monoglycerides and triacylglycerols of fatty acid chains form oil (PérezMonterrosa et al., 2016). Monoglycerides in oleogels are present as two peaks, corresponding to crystallization peaks of monoglycerides saturated and unsaturated components, also related to $\alpha$ and $\beta$ polymorphs, that improves the oil crystallization process (Kamali et al., 2019).

In contrast, for celluloses mixture oleogels, in the control sample, there was only a significant peak at $42{ }^{\circ} \mathrm{C}$ during cooling and small peaks between 61 to $74{ }^{\circ} \mathrm{C}$. Oleogel samples employing soybean oil with the different oleoresins presented only slight changes during heating, observed between the range of 65 to $80{ }^{\circ} \mathrm{C}$, and during the cooling process, a similar shoulder was observed at $46{ }^{\circ} \mathrm{C}$ (Figure 2). The noticeable difference in the thermal behaviour among the two types of oleogels is the difference in melting temperatures for candelilla wax and celluloses (in this case, mainly ethylcellulose). The reported melting temperature for ethylcellulose is $178{ }^{\circ} \mathrm{C}$ (Kordjazi and Ajji, 2020), whereas for candelilla was the melting onset was $54.4{ }^{\circ} \mathrm{C}$ (Winkler-Moser et al., 2019). Although an endothermic peak typically associated with oleogel melting was expected to occur, certain cases were not observed during oleogel heating (Dey et al., 2011). In the same manner, the effect of ethyl cellulose oleogel concentration was observed during the lauric acid crystallization/melting process (specific latent heat release and absorption) (Eisa et al., 2020). 


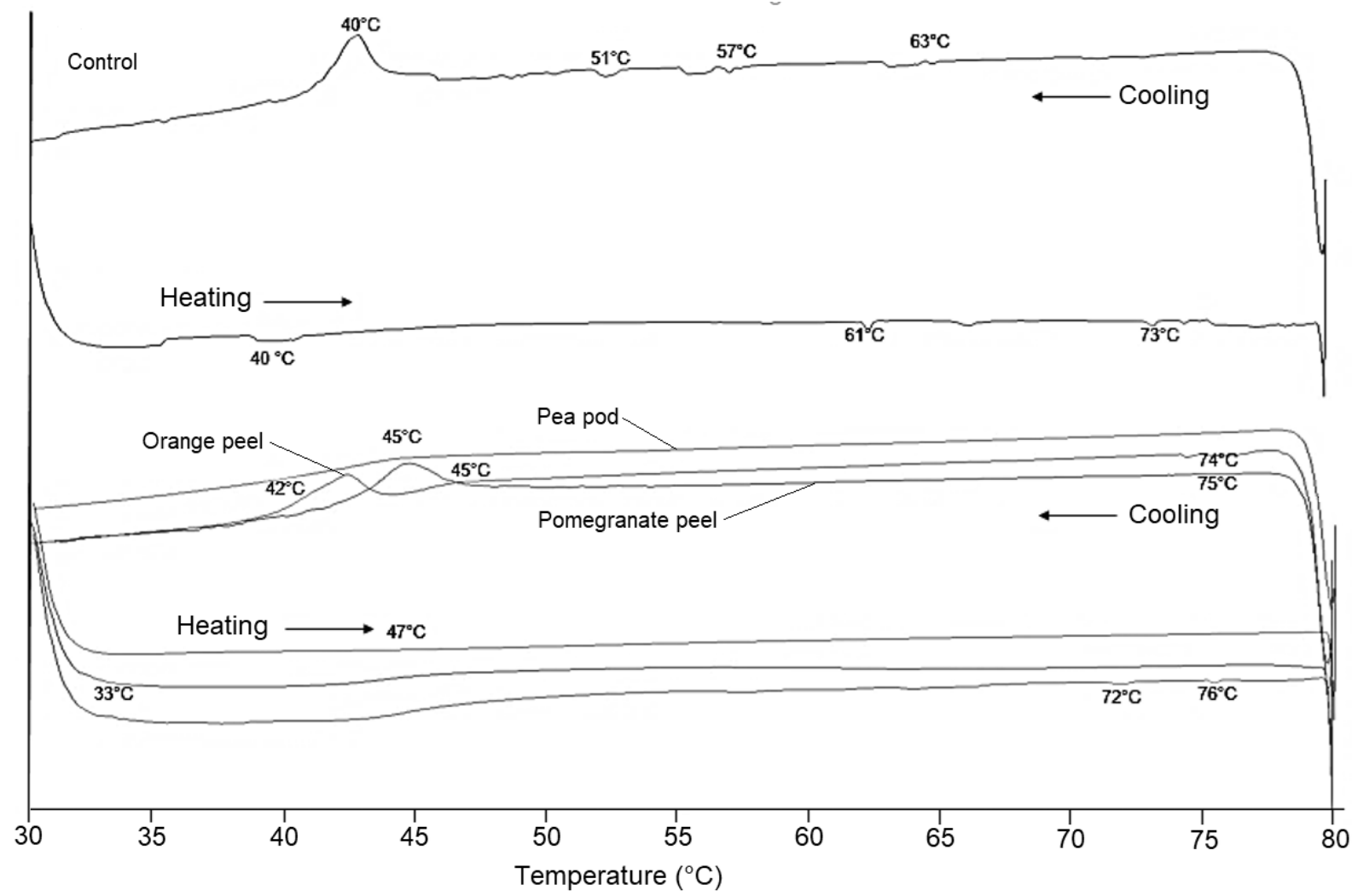

Figure 1. Thermograms of candelilla wax oleogels elaborated with different agro-industrial coproducts of oleoresin during the heating-cooling process.

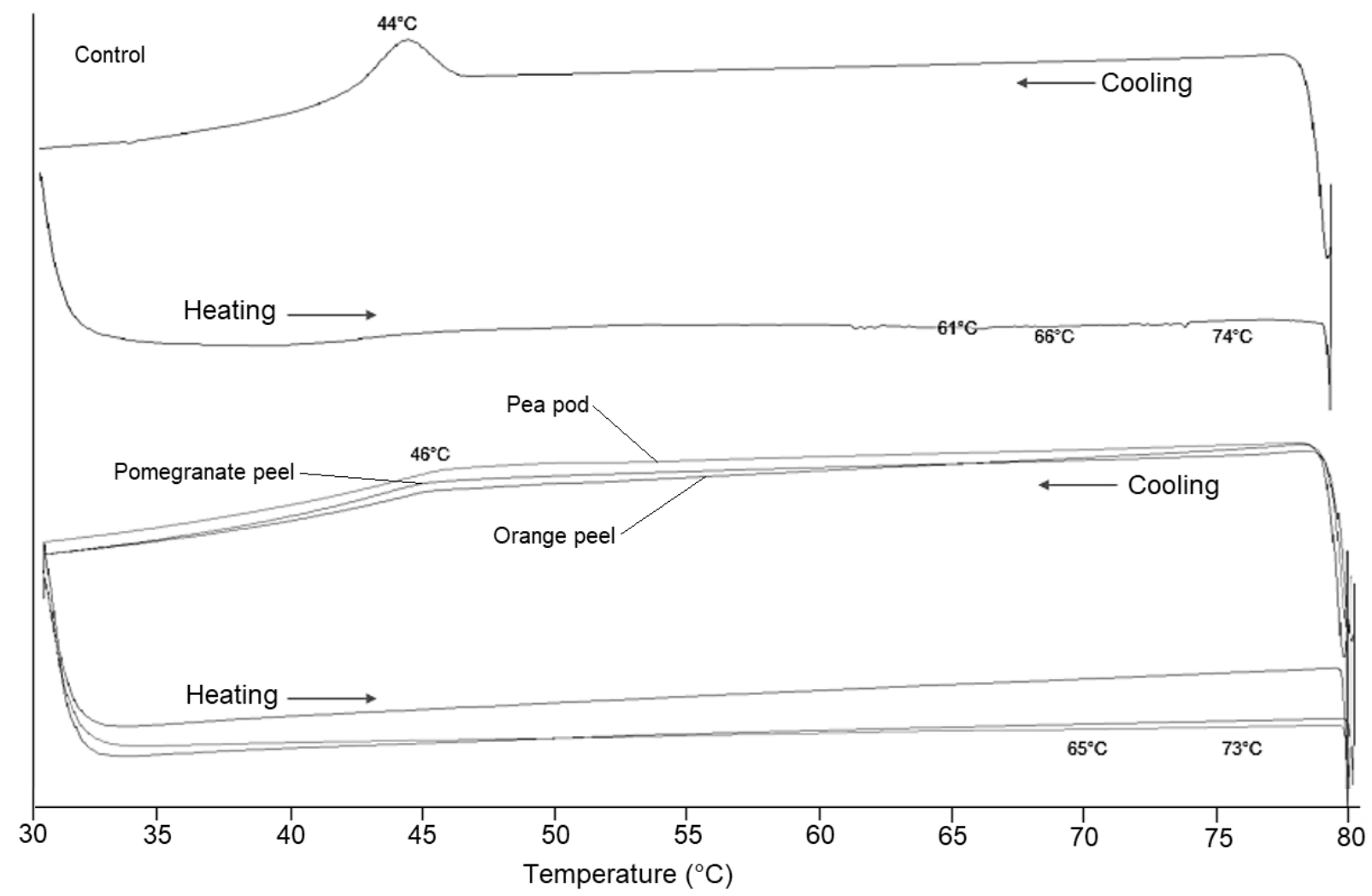

(a)

(b)

Figure 2. Thermograms of celluloses oleogels elaborated with different agro-industrial coproducts of oleoresin during the heating-cooling process 
Oil structuring agents can be classified into low and high molecular weight. Low molecular weight gelators are small molecules (waxes, fatty acids, and alcohol, monoacylglycerol, and ceramides) that form a stable crystal-oil stabilizing network by physical interaction as hydrophobic interaction, hydrogen bonds, and Van der Walls interaction, forming small molecular building blocks, with a high sensitivity to temperature and shear forces.

High molecular weight gelators (proteins and polysaccharides) form a three-dimensional network by hydrogen bond interactions, and oleogel properties strongly depend on polymer concentration, molecular weight, and molecular conformation (Davidovich-Pinhas, 2019).

According to Toro-Vázquez et al. (2007), the development of microcrystalline structures during the sol-gel transition in wax containing oleogels resulted in an order three-dimensional network that retains oil liquid phase and set up the oleogel structure, depending on the shape and size of the gelator molecule (as sterols, phospholipids, etcetera, contained in waxes), affecting the annealing as well, in an ordered crystalline region and/or amorphous regions.

Although it has been reported that the type of oil could affect the melting or crystallization

\section{CONCLUSIONS}

Incorporation of agro-industrial co-products as orange peel, pomegranate peel, or pea pod oleoresins are a viable option to enhance the oxidative stability of edible oils employed in oleogel manufacture. With a higher oxidative capacity, pomegranate peel oleoresin resulted in better oleogels oxidative stability. Thermal changes seem to be not influenced by the type of oleoresin employed, since major changes were related to the temperatures of oleogel (Calligaris et al., 2013; Wang et al., 2020), it seems that waxes exert a more marked effect on the thermal properties of oleogels, since the steric effect of double bonds in triacylglycerols of fatty acid chains form oil that prevents the re-arrangement or accommodation of monoglycerides chains resulting in a less compact structure and lower crystallization temperature due to unsaturated fatty acids in edible oil (PérezMonterrosa et al., 2016). In contrast, in celluloses oleogels, the gelation mechanism and oleogel structure does not imply a highly ordered secondary structure formation due to the absence of thermal transitions during cooling (gelation) and melting (heating), forming a hydrogen bonds-based gel network, different from a typical thermoreversible polymer gelation system, where a characteristic thermal transition which involves the polymer glass transition followed by polymer chains interaction (partition) with the solvent (edible oil) takes place (Davidovich-Pinhas et al., 2015a). Besides, a clear reduction in both sol-gel and gel-sol transition temperatures are attributed to the surfactant action, since surfactants in celluloses oleogels are responsible for an additional organized structure formation due to their amphiphilic nature (Davidovich-Pinhas et al., 2015b).

candelilla wax components influencing oil crystallization during the cooling process, with no celluloses observable effect in the same process. This finding opens the possibility to, on one hand, use oleoresins to improve the oxidative stability of oleogels; and on the other hand, to select the organogelator, waxes, or celluloses, based on thermal properties and other aspects, depending on the further application of oleogel thinking in oleogel thermoreversible capacity.

\section{ACKNOWLEDGEMENTS}

Ferrer-González thanks to Consejo Nacional de Ciencia y Tecnología (CONACYT) the grant for her graduate studies at Tecnológico Nacional de México/TES Ecatepec (Padrón Nacional de Posgrado de Posgrado No. Ref. 1665-0).

\section{REFERENCES}

1. AOAC (1999). Official Method 965.33: Peroxide value of oils and fats. Official Method of Analysis of AOAC International (16th Ed.), Washington, DC: AOAC.

2. Babbar, N., Oberoi, H. S., Sandhu, S. K., \& Bhargav, V. K. (2014). Influence of different solvents in extraction of phenolic compounds from vegetable residues and their evaluation as natural sources of 
antioxidants. Journal of Food Science and Technology, 51: 2568-2575. DOI:10.1007/s13197-0120754-4

3. Blasi, F., \& Cossignani, L. (2020). An overview of natural extracts with antioxidant activity for the improvement of the oxidative stability and shelf life of edible oils. Processes, 8(8): 956. DOI: 10.3390/pr8080956

4. Calligaris, S., Mirolo, G., Da Pieve, S., Arrighetti, S. \& Nicoli, M. C. (2013). Effect of oil type on formation, structure and thermal properties of $\gamma$-oryzanol and $\beta$-sitosterol-based organogels, Food Biophysics, 9: 69-75. DOI: 10.1007/s11483-013-9318-z

5. Davidovich-Pinhas, CP M., Barbut, S., \& Marangoni, A. G. (2015b). The role of surfactants on ethylcellulose oleogel structure and mechanical properties. Carbohydrate Polymers, 127: 355-362. DOI: 10.1016/j.carbpol.2015.03.085

6. Davidovich-Pinhas, M. (2019). Oil structuring using polysaccharides. Current Opinion in Food Science, 27: 29-35. DOI: 10.1016/j.cofs.2019.04.006y

7. Davidovich-Pinhas, M., Barbut, S., \& Marangoni, A. G. (2015a). The gelation of oil using ethyl cellulose. Carbohydrate Polymers, 117: 869-878. DOI: 10.1016/j.carbpol.2014.10.035

8. Der, G., \& Everitt B. S. (2001). A Handbook of Statistical Analyses using SAS. London: Chapman \& Hall/CRC, pp. 101-116.

9. Dey, T., Kim, D. A., \& Marangoni, A. G. (2011) Ethylcellulose Oleogels. In Marangoni, A. G., \& Garti, N (Eds.), Edible Oleogels: Structure and Health Implications (pp. 295-312). Urbana: AOCS Press.

10. Eisa, A. H., Laufer, S., Rosen-Kligvasser, J., \& Davidovich-Pinhas, M. (2020). Stabilization of ethylcellulose oleogel network using lauric acid. European Journal of Lipid Science and Technology, 122(2): 1900044. DOI: 10.1002/ejlt.201900044

11. Fawole, O. A., \& Opara, U. L. (2016). Stability of total phenolic concentration and antioxidant capacity of extracts from pomegranate co-products subjected to in vitro digestion. BMC Complementary and Alternative Medicine, 16:358. DOI: 10.1186/s12906-016-1343-2

12. Freitas, I. R., Machado, T.L.S., Luzia, D.M.M., \& Jorge, N. (2020). Tomato waste extract (Lycopersicon esculentum) as a natural antioxidant in soybean oil under heating. Journal of Bioenergy and Food Science, 7: e2852020JBFS. DOI: 10.18067/jbfs.v7i3.285

13. Ghorbani, M., Ganjloo, A., \& Bimakr, M. (2016). Evaluation the effect of different solvents on total phenolic content and antioxidant activity of pea (Pisum sativum L.) pod extract. Iranian Journal of Food Science and Technology, 14(64): 92-83.

14. Gravelle, A. J., Barbut, S., \& Marangoni, A. G. (2012). Ethylcellulose oleogels: Manufacturing considerations and effects of oil oxidation. Food Research International, 48:578-583. DOI: 10.1016/j.foodres.2012.05.020

15. Gravelle, A. J., Davidovich-Pinhas, M., Zetzl, A.K., Barbut, S., \& Marangoni, A. G. (2016). Influence of solvent quality on the mechanical strength of ethylcellulose oleogels. Carbohydrate Polymers, 135:169-179. DOI:10.1016/j.carbpol.2015.08.050

16. Hwang, H.-S. (2020). A critical review on structures, health effects, oxidative stability, and sensory properties of oleogels. Biocatalysis and Agricultural Biotechnology, 26:101657. DOI: 10.1016/j.bcab.2020.101657

17. Kamali, E., Sahari, M. A., Barzegar, M., \& Gavlighi, H. A. (2019). Novel oleogel formulation based on amaranth oil: Physicochemical characterization. Food Science \& Nutrition, 7(6), 1986-1996. DOI: 10.1002/fsn3.1018

18. Kordjazi, Z., \& Ajji, A. (2020). Partially miscible polymer blends of ethyl cellulose and hydroxyl terminated polybutadiene. Polymer, 211: 123067. DOI: 10.1016/j.polymer.2020.123067 
19. Lim, J., Hwang, H.-S., \& Lee, S. (2017). Oil-structuring characterization of natural waxes in canola oil oleogels: rheological, thermal, and oxidative properties. Applied Biological Chemistry, 60: 17-22. DOI:10.1007/s 13765-016-0243-y

20. Martins, A. J., Cerqueira, M. A., Cunha, R.L., \& Vicente, A.A. (2017). Fortified beeswax oleogels: effect of $\beta$-carotene on gel structure and oxidative stability. Food \& Function, 8: 4241-4250. DOI:10.1039/c7fo00953d

21. Mateos-Aparicio, I., Redondo-Cuenca, A., \& Villanueva-Suárez, M. J. (2012). Broad bean and pea by-products as sources of fibre-rich ingredients: potential antioxidant activity measured in vitro. Journal of the Science of Food and Agriculture, 92: 697-703. DOI: 10.1002/jsfa.4633

22. Naumovski, N., Ranadheera, S., Thomas, J., Georgousopoulou, E., \& Mellor, D. (2017). Bioactive Compounds in agricultural and Food production Waste. In Vuong, Q.V. (Ed.), Utilisation of Bioactive Compounds from Agricultural and Food Waste (pp- 1-26). Boca Raton: CRC Press. DOI: 10.1201/9781315151540-1

23. Öğütcü, M., Arifoğlu, N., \& Yilmaz, E (2015). Preparation and characterization of virgin olive oil-beeswax oleogel emulsion products. Journal of American Oil Chemists' Society, 92: 459-471. DOI:10.1007/s 11746-015-2615-6

24. Park, J.-H., Lee, M, \& Park, E (2014). Antioxidant activity of orange flesh and peel extracted with various solvents. Preventive Nutrition and Food Science, 19: 291. DOI: 10.3746/pnf.2014.19.4.291

25. Pérez-Monterrosa, E. J., Ciro-Velásquez, H. J., \& Arango-Tobón, J. C. (2016). Study of the crystallization and polymorphic structures formed in oleogels from avocado oil. Revista de la Facultad Nacional de Agronomía de Medellín, 69: 7945-7954. DOI: 10.15446/rfna.v69n2.59139

26. Re, R., Pellegrini, N., Proteggente, A., Pannala, A., Yang, M., \& Rice-Evans, C. (1999). Antioxidant activity applying an improved ABTS radical cation decoloration assay. Free Radical Biology and Medicine, 26: 1231-1237. DOI: 10.1016/S0891-5849(98)00315-3

27. Salta, F. N., Mylona, A., Chiou, A., Boskou, G., \& Andrikopoulos, N. K. (2007). Oxidative stability of edible vegetable oils enriched in polyphenols with olive leaf extract. Food Science and Technology International, 13(6): 413-421. DOI: 10.1177/1082013208089563

28. Singlenton, V., \& Rossi, J. (1965). Colorimetry of total phenolics with phosphomolybdic phosphotungstic acid reagents. American Journal of Enology and Viticulture, 16: 144-158.

29. Toro-Vázquez, J. F., Morales-Rueda, A., Dibildox-Alvarado, E., Charo-Alonso, M., Alonzo-Macías, M., \& González-Chávez, M. M. (2007). Thermal and textural properties of organogels developed by Candelilla wax in safflower oil. Journal of American Oil Chemists' Society, 84: 989-1000. DOI: 10.1007/s11746-007-1139-0

30. Totosaus, A., González-González, R., \& Fragoso, M. (2016). Influence of the type of cellulosic derivatives on texture, oxidative and thermal stability of soybean oil oleogel. Grasas y Aceites, 67: e152. DOI: $10.3989 / g y a .0440161$

31. Wang, X., Wang, S.-J., Nan, Y., \& Liu, G.-Q. (2020). The effects of oil type and crystallization temperature on the physical properties of vitamin C-loaded oleogels prepared by an emulsiontemplated approach. Food \& Function, 11: 8028-8037. DOI: 10.1039/C9FO02479D

32. Winkler-Moser, J. K., Anderson, J., Felker, F. C., \& Hwang, H.-S. (2019). Physical properties of beeswax, sunflower wax, and candelilla wax mixtures and oleogels. Journal of the American Oil Chemists' Society, 96: 1125-1142. DOI: 10.1002/aocs.12280

33. Yi, B., Kim, M. J., Lee, S. Y., \& Lee, J. (2017). Physicochemical properties and oxidative stability of oleogels made of carnauba wax with canola oil or beeswax with grapeseed oil. Food Science and Biotechnology, 26: 79-87. DOI: 10.1007/s10068-017-0011-8 
34. Yun, J., \& Surh, J. (2012). Fatty acid composition a predictor for the oxidation stability of Korean vegetable oils with or without induced oxidative stress. Preventive Nutrition and Food Science, 17: 158-165. DOI: 10.3746/pnf.2012.17.2.15 